\title{
A Development of an Educational Game for Learning a Concept of King Bhumibol's Philosophy of Sufficiency Economy
}

\author{
Worasit Choochaiwattana ${ }^{1+}$, Winyu Niranatlamphong ${ }^{1}$, Anuwat Ruttanasomboon ${ }^{1}$, \\ Wicha Charoensuk ${ }^{1}$, Phattara Rattanamoranon ${ }^{1}$, Aurawan Imsombat ${ }^{1}$ and Jittanard Sangkrajang ${ }^{2}$ \\ ${ }^{1}$ College of Creative Design and Entertainment Technology, Dhurakij Pundit University, Bangkok, Thailand \\ ${ }^{2}$ Faculty of Architecture, King Mongkut's Institute of Technology Ladkrabang, Bangkok, Thailand
}

\begin{abstract}
Using technology to enhance learning is increasingly popular. An educational game shows positive impacts on learners. This paper aims at developing an educational game for learning a concept of King Bhumibol's Philosophy of Sufficiency Economy. The game, named "Thai Farmers' Way of Life" is developed. It comprises of three stages that are Stage 1 Artificial Rain, Stage 2 Wastewater Treatment, and Stage 3 Soil Aggravation. This game simulates a life of Thai farmers. Thus, the player must turn an empty farmland into a plentiful farmland using the "New Theory of Agriculture". The evaluation results show that this interactive education game help its player to understand the King Bhumibol's Philosophy of Sufficiency Economy.
\end{abstract}

Keywords: Educational Game, Game Based Learning, King Bhumibol, Sufficiency Economy Philosophy

\section{Motivation}

The role of technology has become a prominent feature in human daily life. At the present time, people in all ages use computer and internet with ease and for various purposes. Searching for information, purchasing goods or services, communicating with others, and are the most common usage. In addition, using technology to enhance learning is also increasingly popular. It is considered as innovative tools that provide an interesting procedure in an educational area [1]. The usage of computer game is one of examples that show promising results for improving student learning abilities [2].

Many people love playing computer game because an enjoyment while playing [3]. Applying an enjoyment for serious activities such as learning can provide a positive impact on children [4]. Results from research projects revealed that playing computer game encourages critical thinking [5][6]. Under the fun environment, learning on difficult topics such as Mathematic [7] can be effective because it boosts student's motivation [8][9]. In addition, Morsi and Mull [10] showed evidence that gaming in education also has positive impact on a wide range of people with diverse learning including college students.

This research paper aims at developing an educational game for learning a concept of King Bhumibol's Philosophy of Sufficiency Economy (PSE) and examining whether a game can improve students' understanding about PSE concept and King Bhumibol's initiative projects for rural development.

\section{King Bhumibol's Philosophy of Sufficiency Economy}

According to [11], the King Bhumibol Adulyadel talked about the Philosophy of Sufficiency Economy to Thai people via national television live broadcasting on December 4, 1997. The ultimate goal of the philosophy is to balance way of living. The philosophy has three main principles which are Moderation, Reasonableness, and self-immunity with two underlying conditions which are knowledge and moral

+ Corresponding author. Tel.: + 66-2-954-7300 ext. 252 fax: +66-2-954-7902.

E-mail address: worasit.cha@dpu.ac.th 
principles. By practicing these three main principles with two underlying conditions, people would be able to live in a sustainable society and environment. This philosophy aims at improving human well-being as a development goal. During the reign of King Bhumibol, his majesty the king had launched more than 4,000 development and social welfare projects. Many of them were examples that reflect the philosophy of sufficiency economy.

\section{Methodology}

To learn about King Bhumibol's Philosophy of Sufficiency Economy, one of his majesty the king's projects called "New Theory of Agriculture" has been selected as a game theme. This project is a good example to describe the philosophy of sufficiency economy because the main purpose of the New Theory Agriculture is to make famers more self-reliant through a holistic management of their land, while living harmoniously with nature and within society.

\subsection{Game Design}

Thai Farmers' Way of Life is an interactive education game that simulate a life of Thai farmers. The main story of the game takes place in an empty farmland. The mission of the game is to turn an empty farmland into a plentiful farmland using the "New Theory of Agriculture". The farmland is divided into 4 sections as following

- $10 \%$ of the land for animal raising

- $30 \%$ of the land for fruit and plant growing for consumption and distribution

- $30 \%$ of the land for pond and fish raising for consumption and distribution

- $30 \%$ of the land for rice planting

The figure 1 shows the main interface of Thai Farmers' Way of Life game. The Thai Farmers' Way of Life game is composed of three different but related stages which are "Artificial Rain", "Wastewater Treatment", and "Soil Aggravation". Each stage represents basic principles on how to prepare the farm according to in the New Theory of Agriculture.

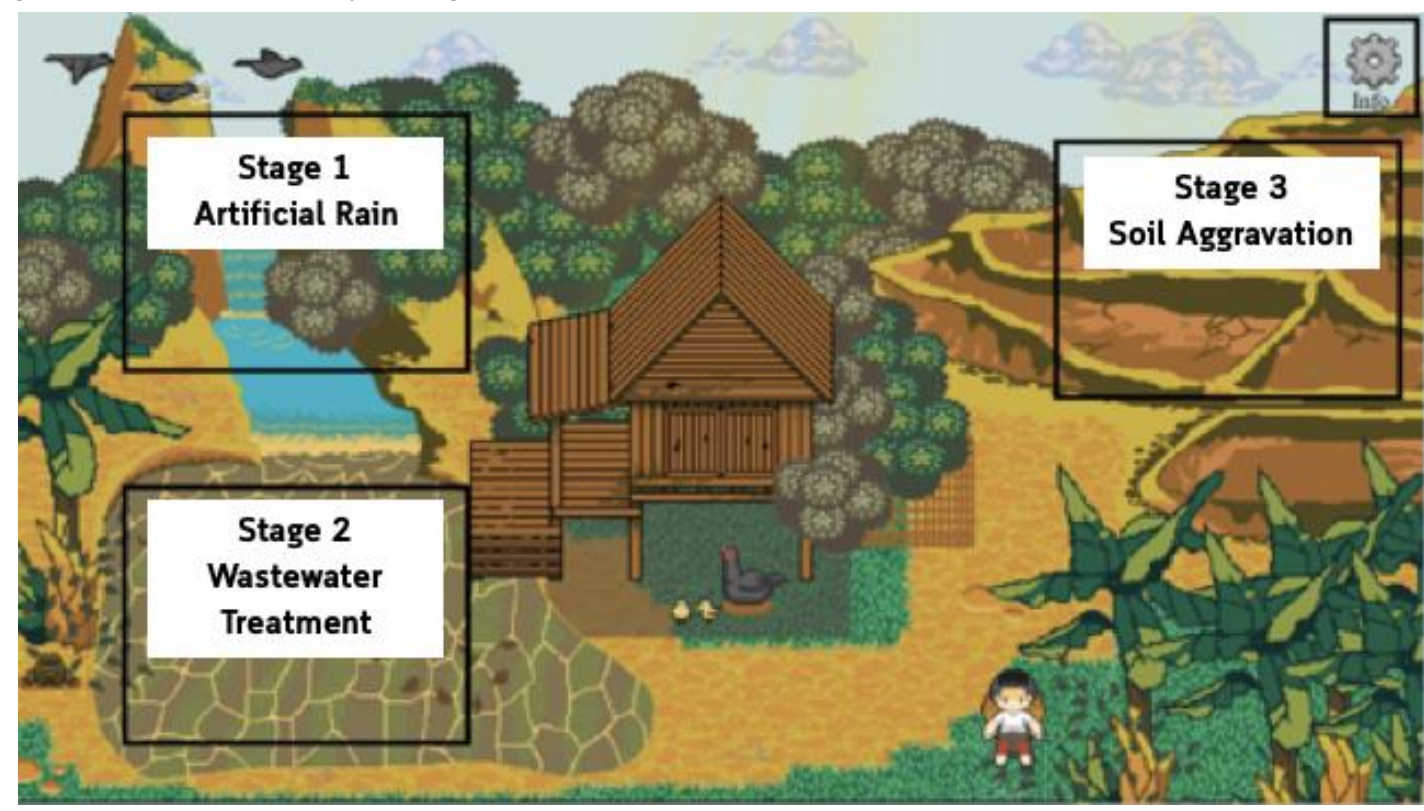

Fig. 1: Main Interface Thai Farmers’ Way of Life Game.

In stage 1 "Artificial Rain", the main objective of this stage is to understand a procedure on how to make artificial rain. During playing on this stage, a player will learn about the Thailand Royal Rainmaking Project which is initiated in November 1955 by King Bhumibol Adulyadej [12]. The figure 2 shows the interface for the stage 1 . 


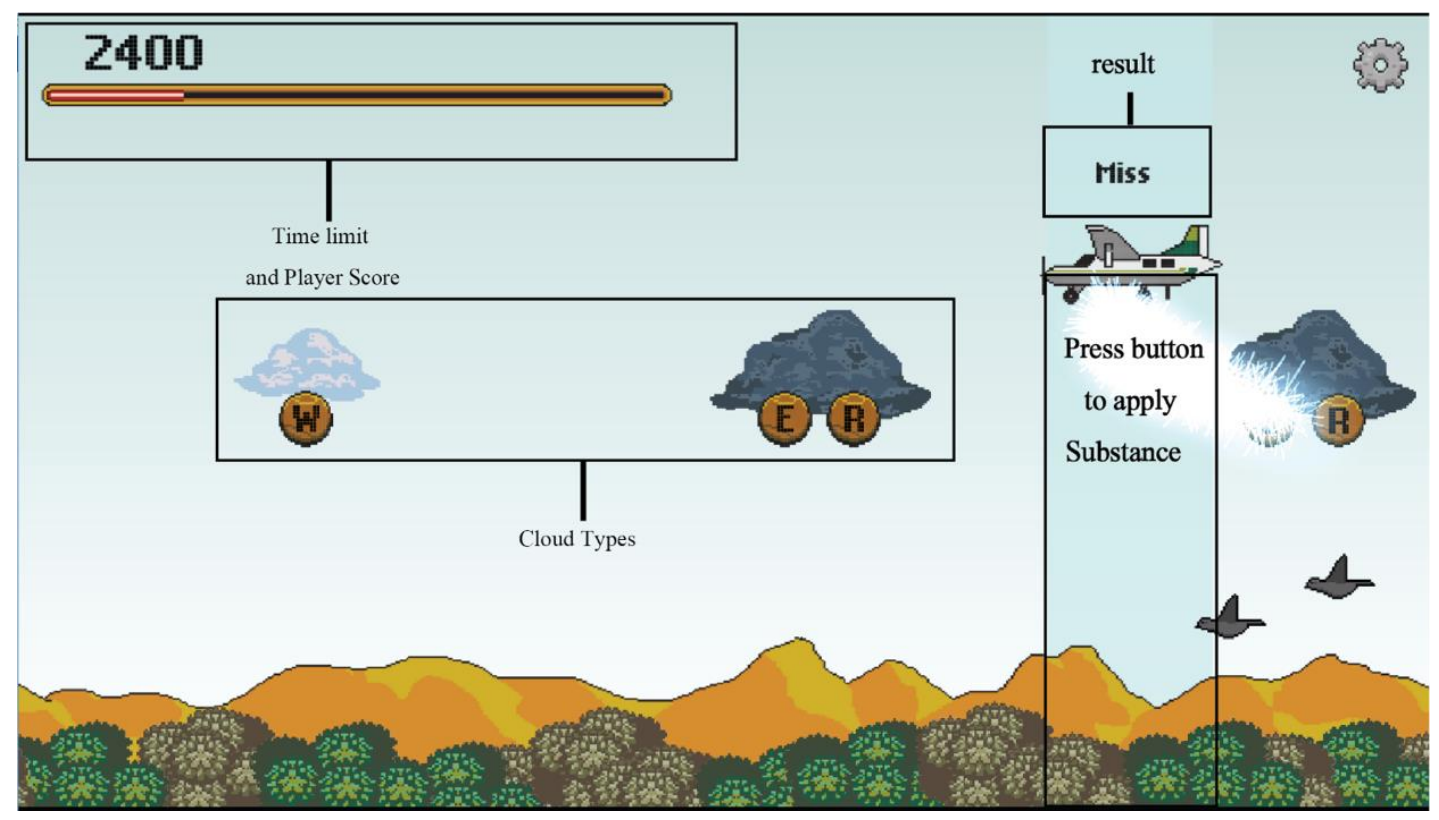

Fig. 2: Stag 1 Artificial Rain

In stage 2 "Wastewater Treatment" ", the main objective of this stage is to understand a procedure on how to alleviate water pollution. During playing on this stage, a player will learn about King Bhumibol's invention of the Chaipattana Aerator [13] and the process of how to improve water quality. The figure 3 shows the interface for the stage 2 .

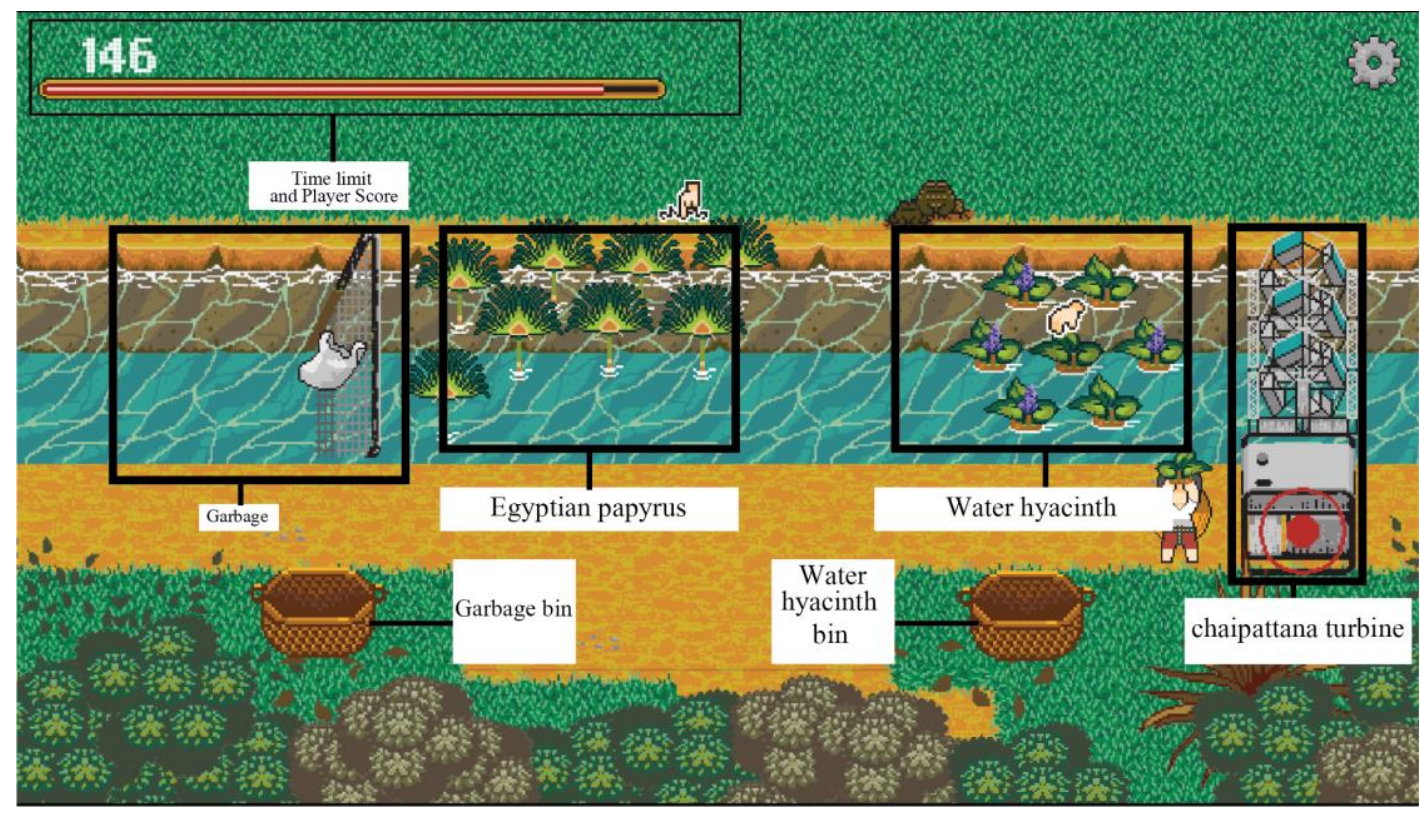

Fig. 3: Stag 2 Wastewater Treatment

In stage 3 "Soil Aggravation", the main objective of this stage is to understand a procedure on how to improve soil quality and prepare the soil for plantation. During playing on this stage, a player will learn about King Bhumibol's initiative on "Klaeng Din (Soil Aggravation)" [14]. The figure 4 shows the interface for the stage 3 . 


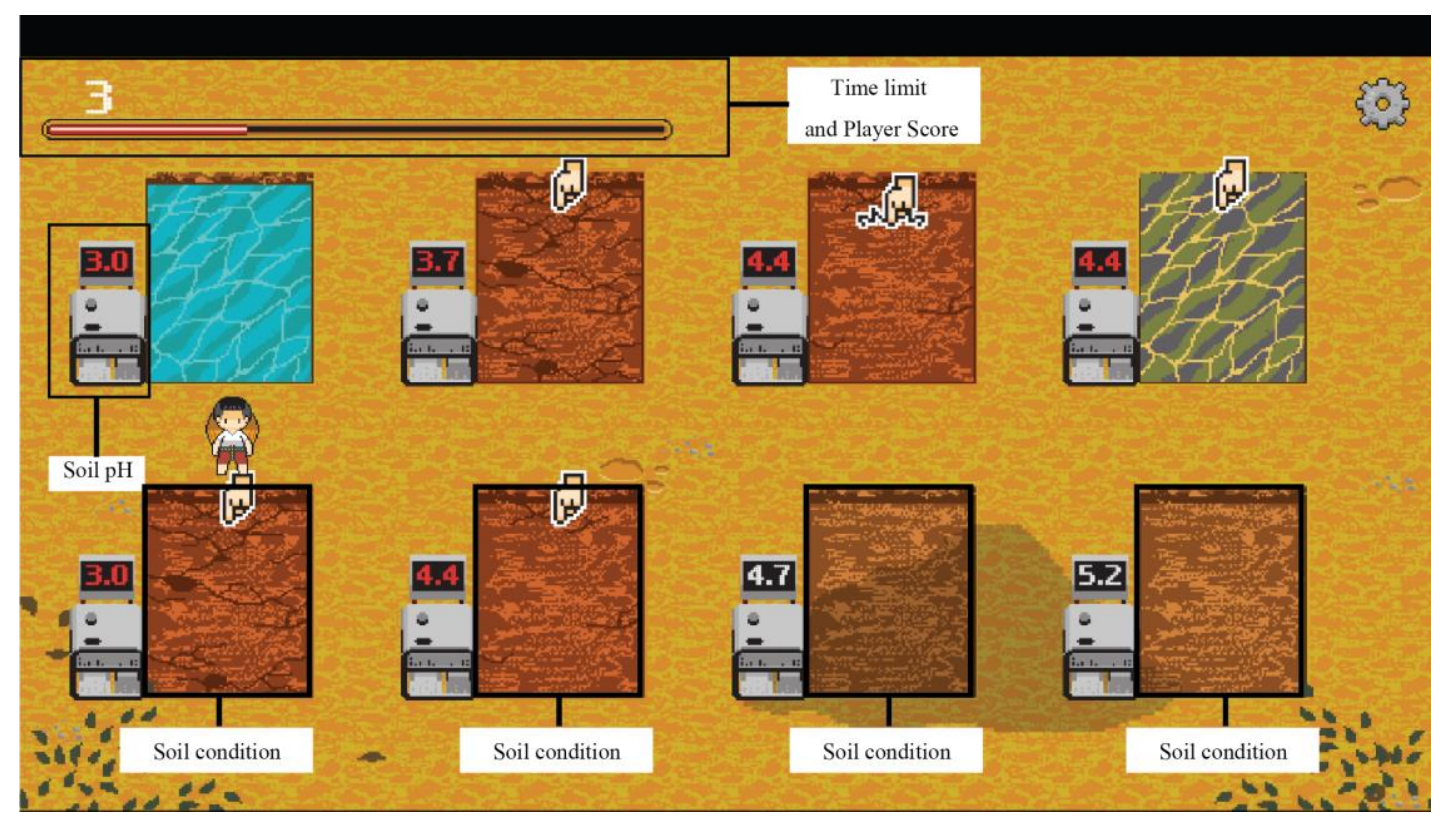

Fig. 4: Stag 3 Soil Aggravation

\subsection{Experimental Setting}

To evaluate the Thai Farmers' Way of Life game, a group of students and staffs from College of Creative Design and Entertainment Technology, Dhurakij Pundit University were recruited to be subjects in an experiment. They were first asked whether they understand the Philosophy of Sufficiency Economy and the New Theory of Agriculture. They were then asked to play the Thai Farmers' Way of Life game. At the end of the experiment, they were asked to evaluate the game and determine whether the game provide them a better understanding of the Philosophy of Sufficiency Economy and the New Theory of Agriculture.

\section{Evaluation Results}

A total of fifteen students and staffs were subjects in the experiment. $80 \%$ of participants are male. All of participants said that they have heard about the Philosophy of Sufficiency Economy but $66.7 \%$ of them said that they fully understood the philosophy. However, 50\% of them said that they have heard about the New Theory of Agriculture but not sure whether they fully understood the theory.

After finish playing game, the list of questions were asked the participants. The evaluation result are as follows:

- $66.67 \%$ of participants said that they moderately understood the Philosophy of Sufficiency Economy and the New Theory of Agriculture respectively, 26.67\% said that they considerably understood the philosophy and the theory, while $6.67 \%$ said that they slightly understood the philosophy and the theory.

- $40.00 \%$ of participants said that they considerably understood about the King Bhumibol's initiative projects for rural development, $33.33 \%$ said that they moderately understood about the projects, $20.00 \%$ said that they slightly understood the projects, while $6.67 \%$ said that they fully understood about the projects.

Finally, the participants were asked to provide comments and suggestions on the Thai Farmers' Way of Life game. The comments and suggestions are as follows:

- I love stage 1 Artificial Rain. It's fun to play.

- This game have made me understand the King Bhumibol's initiative projects for rural development.

- I like a graphic design of this game. Easy to follow and understand.

- Please add more features e.g. online playing with friend.

- Some parts of the game provide a lot of unnecessary information.

- Get confused at the beginning. But after playing for a while the game is fun to play. 


\section{Conclusion and Future Work}

The Thai Farmers' Way of Life is an interactive education game for students who interest in learning about the King Bhumibol's Philosophy of Sufficiency Economy. It comprises of three stages that are Stage 1 Artificial Rain, Stage 2 Wastewater Treatment, and Stage 3 Soil Aggravation. This game simulate a life of Thai farmers. Thus, the player must turn an empty farmland into a plentiful farmland using the "New Theory of Agriculture". The evaluation results show that this interactive education game help its player to understand the King Bhumibol's Philosophy of Sufficiency Economy. To make this game more interesting, the mobile version of this game should be developed. More feathers need to be included.

\section{References}

[1] V. Drosos, A. Alexandri, D. Tsolis, and C. Alexakos. A 3D Serious Game for Cultural Education. In Proc. of the $8^{\text {th }}$ International Conference on Information, Intelligence, Systems \& Applications (IISA). Larnaca, Cyprus. 2017, pp. 1-5.

[2] K. Maragos and M. Grigoriadou. Tracing the Characteristics, Motives and Potential of the Use of Digital Games in Education. In Proc. of the $4^{\text {th }}$ Panhellenic Conference with International Participation "ICT in Education". 2004, pp.103-112.

[3] K. Kiili. Digital Game-Based Learning: Toward an Experiential Gaming Model. Internet and Higher Education. 2005, 8(1): 13-24.

[4] Q. Gui and S. Zhang. "Education-Based Social Game": The New Ways of Developing Educational Games. In Proc. of the $6^{\text {th }}$ International Conference on Digital Content, Multimedia Technology and its Applications. Seoul, Korea. 2010, pp. 50-52.

[5] C. P. Lim, D. Nonis, and J. Hedberg. Gaming in a 3D Multiuser Virtual Environment Engaging Students in Science Lessons. British Journal of Educational Technology. 2006, 37(2): 211-231.

[6] Y. Inal and K. Cagiltay. Flow Experiences of Children in and Interactive Social Game Environment. British Journal of Educational Technology. 2007, 38(3): 455-464.

[7] M. Hartono, M.A. Candramata, K.N. Adhyatmoko, and B. Yulianto. Math Education Game for Primary School. In Proc. of the International Conference on Information Management and Technology (ICIMTech). Bandung, Indonesia. 2016, pp. 93-96.

[8] M.M. Elaish, N.A Ghani, L. Shuib, and A. Al-Haiqi. Development of a Mobile Game Application to Boost Students' Motivation in Learning English Vocabulary. IEEE Access. 2019, 7: 13326-13337.

[9] B. Kutun and W. Schmidt. Rallye Game: Learning by Playing with Racing Cars. In Proc. of the $10^{\text {th }}$ International Conference on Virtual World and Games for Serious Applications (VS-Games). Wurzburg, Germany. 2018, pp.1-2.

[10] R. Morsi and S. Mull. Digital Lockdown: A 3D Adventure Game for Engineering Education. In Proc. of IEEE Frontiers in Education Conference. El Paso, Texas, USA. 2015, pp.1-4.

[11] P. Mongsawad. The Philosophy of the Sufficiency Economy: A Contribution to the Theory of Development. AsiaPacific Development Journal. 2010, 17(1): 123-143.

[12] Royal Rainmaking Project. Accessed : 2019-02-14. [Online] Available: https://en.wikipedia.org/wiki/Royal_Rainmaking_Project

[13] Environment Quality Improvement. Accessed : 2019-02-14. [Online] Available: http://www.chaipat.or.th/eng/ourwork/environmental-quality-improvement.html

[14] Concept and Theories on Soil Accessed : 2019-02-14. [Online] Available: http://www.chaipat.or.th/eng/conceptstheories/soil-improvement.html 